\title{
O que vem depois dos "legal transplants"? Uma análise do processo penal brasileiro atual à luz de direito comparado
}

\section{What comes after the "legal transplants" An analysis of the current Brazilian criminal procedure in light of comparative law}

\section{Renato Stanziola Vieira ${ }^{1}$}

Universidade de São Paulo - São Paulo/SP

renatovieira@kv.adv.br

lattes.cnpq.br/0404579976824382

orcid.org/0000-0001-6910-958X

Resumo: O presente estudo pretende tratar do processo penal comparado à luz da conhecida expressão de "transplante jurídico". Nesse sentido aqui se diz, num primeiro momento, do atual estágio da ciência do direito comparado. Depois se trata de possíveis aspectos críticos que podem ser lembrados em países latino-americanos, incluindo o Brasil. Por fim, com olhos ao processo penal e autores que se debruçaram no tema do processo penal comparado, assume-se posição crítica quanto ao cenário de algumas reformas do processo penal brasileiro atual.

Palavras-chave: direito comparado; processo penal; transplantes jurídicos; América Latina; reforma processual penal.

ABSTRACT: The present study aims to focus the comparative criminal procedure in the light of the well known expression of "legal transplants". In this meaning here is said, at a first moment, about the actual stage of the science of comparative law. After that follow the possible critical aspects which can be remembered in countries of Latin America, including Brazil. At the end, with eyes at criminal procedure and authors who had shared attention to the theme of comparative

1 Doutorando e mestre em Direito Processual Penal pela USP, Mestre em Direito Constitucional pela PUCSP, membro do IBCCRIM e do IBDP, advogado. 
criminal procedure, it is assumed a critical position related to the scenario of some legal reforms in the ongoing Brazilian criminal procedure.

KEYWORDS: comparative law; criminal procedure; legal transplants; Latin America; criminal procedure reform.

SUMÁRIO: Introdução e proposta de abordagem. 1. Transplantes, transferências, irritantes, traduções. 2. As metáforas: o 'antes' e o 'depois'. 3. Depois dos transplantes: o falso problema do cabimento na análise do sucesso. 4. Processo penal brasileiro atual à luz do direito comparado: um pastiche legal. Conclusões. Bibliografia.

... disseram que eu voltei americanizada...

(Luiz Peixoto e Vicente Paiva)

\section{INTRODUÇÃO E PROPOSTA DE ABORDAGEM}

Pensar em direito comparado esgota-se na visão do outro, do diferente, para o encontro com si mesmo?

Em outras palavras, basta o cotejamento de assim chamados 'sistemas' (admitida classificação que leva em conta o tipo ideal weberiano como método de estudo de sistemas jurídicos $\operatorname{comparados}^{2}$ ) com pretensão discursiva que não vai além da observação e descrição de cada um deles? $\mathrm{Ou}$, mais que isso, o direito comparado é ferramenta que não se desatrela de certa carga valorativa com potência maior do que a de permitir a observação de algo, de forma a incidir no objeto analisado para ali causar

2 Um exemplo acabado desse método se pode observar em: DAMAŠKA, Mirjan. The faces of justice and State authority: a comparative approach to the legal process. New Haven \& London: Yale University Press, 1986. Assim também: LANGER, Maximo. In the beginning was Fortescue: on the Intelectual Origins of the Adversarial and Inquisitorial Systems and Common and Civil Law in Comparative Criminal Procedure. In: ACKERMAN, Bruce; AMBOS, Kai; SIKIRIĆ, Hrvoje (eds.). Visions of Justice. Liber Amicorum Mirjam Damaška. Cunker \& Humblot: Berlim, 2016. p. 276-80. 
transformação ou dali adquirir motivação de sua própria transformação? O direito comparado é, além de descritivo, potencialmente normativo?

O estudo de sistemas, de comportamentos dos atores, e das permanências/modificações jurídicas e sociais, como características que podem, aqui ou ali, se constituírem como ferramental característico do chamado direito comparado, não é uma mera aventura de observação. Não é nem uma "aventura", porque supõe cabedal metodológico suficiente e, portanto, necessidade de verificação de seu uso; e nem muito menos algo que se encerra na observação.

Além de ser em si um método de estudo científico - e, no campo das ciências humanas, com toda a carga de verificabilidade empírica a validar ou contestar premissas e conclusões - pressupõe o manejo de instrumentais próprios para que se desenvolva como válido. As ferramentas do assim chamado "direito comparado" acarretam que seus diagnósticos (a partir das premissas das quais cada comparatista parta) alterem ou solidifiquem estruturas, além de jurídicas, sociais, em cada sociedade analisada.

Tão proliferados são os estudos atuais de direito comparado que a primeira dificuldade seria já situar este texto dentro de algum específico ramo do direito: constitucional, processual penal ou mesmo teoria do direito ou sociologia do direito.

Outro obstáculo a um percurso que se propõe aqui a ter um início um meio e um fim é a escolha do recorte dentro da área propriamente dita: é de comportamento judicial comparado que se cuida (v.g., o papel dos tribunais), ou é de mecânica legislativa (pacotes legislativos de um a outro país), isto é, das consequências da introjeção - ou não - em um determinado país da modificação do papel dos tribunais ou, diversamente, da alteração legislativa?

Nenhuma das abordagens é inválida, e nem menos ou mais importante, pois em certa medida podem ser complementares. Afinal, o funcionamento de cada estrutura (sua engrenagem) funciona melhor ou pior com o comprometimento não só do aparato legislativo (com introjeção de novas leis) como com a resposta dos seus atores a partir da observação para o que está fora de cada país ${ }^{3}$.

3 Elisabetta Grande: “às vezes transplantes ocorrem no nível legislativo, às vezes no nível das cortes, e em outros momentos eles majoritária ou 
O que se pretende fazer aqui é elaborar um estudo sobre a mecânica do direito comparado especificamente voltada ao processo penal brasileiro atual. Não se tratará neste texto de comportamento judicial, mas da proliferação de características mais ligadas a determinados sistemas jurídicos, que vagarosamente penetram no direito positivo brasileiro.

Essa análise não prescindirá da abordagem feita por autores atentos ao contexto mais amplo da América Latina, e que inclusive dialogam não só com o processo penal, mas com outras áreas em que os chamados "transplantes"4 jurídicos se dão, como por exemplo, direito constitucional.

Primeiro se cuidará da potencialidade (ao menos discursiva) do uso de metáforas tão difundidas quanto qualitativamente exploradas por autores variados como piores ou melhores do ponto de vista de método de estudo em direito comparado. A apropriação de um ou outro termo por autores diversos não é algo asséptico ou neutro, como não é o próprio desenvolvimento das comparações entre sistemas jurídicos com vistas às acomodações num ou noutro sentido.

Depois se tratará de uma sutileza que é percebida mais no campo da sociologia jurídica e não tanto na abordagem exclusivamente de direito positivo, que são as consequências da introjeção em cada sistema jurídico de determinadas normas externas. Nesse ponto, o que se imagina diagnosticar é um segundo passo, de aceitação, refutação, transformação ou continuísmo de normas a partir do advento de mudanças legislativas com arrimo no direito comparado. A ciência, aqui, vale tanto para a aceitação quanto para a resistência à importação dos modelos.

Ao final, a conclusão específica sobre o direito processual penal brasileiro não terá pretensões maiores do que abordar o direito comparado como método de estudo e desenvolvimento do direito positivo, ao mesmo tempo em que se pretenderá oferecer subsídio crítico e que vá além do meramente observatório para a concordância ou a discordância da adoção de novos modelos.

exclusivamente operam no nível da doutrina." (GRANDE, Elisabetta. Legal Transplants and the inoculation effect. How American criminal procedure has affected continental Europe. The American Journal of Comparative Law, v. 64, p. 583-618, 2016. p. 585).

4 Abaixo se descerá às minúcias do uso (e desuso) desse termo. 


\section{TRANSPLANTES, TRANSFERÊNCIAS, IRRITANTES, TRADUÇõES}

No desenvolvimento do direito comparado, ao menos desde os estudos de Alan Watson, o termo "transplantes jurídicos"5 se consagrou como uma expressão icônica. Atualmente há quem tome a terminologia difundida por Watson como um "paradigma central em direito comparado"6 ou como um topos clássico em direito comparado ${ }^{7}$.

Tal expressão, contudo, tem sido objeto de enorme exploração conceitual à vista do lado didático que potencializa quando se imagina a utilização de modelos jurídicos estrangeiros por países os mais diversos. Também é alvo de críticas (internas) que partem da exploração propriamente conceitual e de assimilação de aspectos biológicos 'transpostos' a modelos jurídicos. Mais radical ainda, há a crítica (externa) que chega a apontar sua impossibilidade ${ }^{8}$.

Nesse estudo se tratará das chamadas críticas internas, que não destroem a ideia de fundo sobre a qual se erigiu o conceito, mas cingem-se a meditar sobre outras metáforas para as estratégias de utilização de regras jurídicas que são transpostas de um país a outro.

O lado externo da crítica não é aqui abordado mesmo porque não parece ter sustentação a negativa cabal da influência de um sistema em outro, do ponto de vista de cada conformação legislativa; e não haveria

5 Sobre isso: WATSON, Alan. Legal transplants. An approach to comparative law. 2. ed. Athens and London: The University of Georgia Press, 1993.

6 GRAZIADEI. Michele. Comparative Law as the Study of Transplants and Receptions. In: REINMANN, Mathias; ZIMMERMANN, Reinhard (eds.). The Oxford Handbook of Comparative Law. Oxford: Oxford University Press, 2006. p. 443. John W. Cairns traça desenvolvimento histórico da expressão "transplante jurídico", nomeando mais de um autor que precedeu a Watson em sua utilização. Depois da consagração aborda vertente crítica, principalmente, a de Pierre Legrand, sobre seu uso. Esse autor toma a obra de Watson como "seminal" em direito comparado (CAIRNS, John W. Watson, Walton, and the History of Legal Transplants. Georgia Journal of International and Comparative Law, v. 41, n. 3, p. 637-696, 2014. p. 358-64)

7 GRANDE, Elisabetta. Legal Transplants and the inoculation effect. How American criminal procedure has affected continental Europe. The American Journal of Comparative Law, v. 64, p. 583-618, 2016. p. 585.

8 LEGRAND, Pierre. The Impossibility of legal transplants. Maastricht Journal of European and Comparative Law, v. 4, n. 2, p. 111-124, jun. 1997. p. 111-124. 
espaço aqui para descer a minúcias sobre os detalhamentos críticos, sobretudo, da obra de Pierre Legrand.

O diálogo que se estabelece com os transplantes jurídicos não desmerece a ideia de fundo, que é o estabelecimento do método didático de estudo do que o próprio Alan Watson viu como o "movimento de uma regra ou de um sistema jurídico de um país a outro, ou de um povo a outro". ${ }^{9}$

A ideia não é a de negar a constatação empírica de adoção, por um determinado país, das regras jurídicas que existem em outro, incorporando-as, mesmo porque chame-se como se quiser o fenômeno de tal transposição, haverá sempre uma relação de autoridade científica ou de hierarquia (seja velada ou expressa), de influência, de um país em outro como catapulta para a adoção de um ou outro sistema, uma vez que a mirada seja a do direito comparado.

As críticas partem de pretensões de melhoramento do conceito ligado a essa circulação de modelos jurídicos para propor, em cada contribuição autoral, terminologias mais adequadas a depender das premissas do 'como' e do 'por quê' se adotar essa ou aquela alteração de sistemas jurídicos.

Aqui se pode lembrar de Otto Kahn-Freund, que, valendo-se ainda da expressão "transplante jurídico", preocupava-se com o direito comparado como um instrumento de reforma jurídica, e se perguntava sobre os usos e desusos de modelos jurídicos no processo legislativo de quais condições deveriam ser preenchidas para se fazer desejável ou possível tal alteração ${ }^{10}$. Já então se disse - em crítica que depois virá a ecoar em vários autores - que "transferir parte de um organismo vivo e transferir parte de um mecanismo são comparáveis em propósito, mas em nada mais." 11

Otto Kahn-Freund tomou o "transplante" como sinônimo de "transferência” em matéria de modificações legislativas a partir do direito

\footnotetext{
9 WATSON, Alan. Legal transplants. An Approach to Comparative Law. 2. ed. London: University of Georgia Press, 1993. p. 21.

10 KAHN-FREUND, Otto. On uses and misuses of comparative law. The Modern Law Review, v. 37, n. 1, p. 1-27, jan. 1974. p.1-2

11 Ibidem, p. 5.
} 
comparado ${ }^{12}$. Acredita-se que tenha sido o primeiro a utilizar não a metáfora "transplante" como adequada, mas a de "transferência"13.

Gunther Teubner, a partir de claro diálogo com Alan Watson, preferiu se valer da expressão "legal irritant" em detrimento de "legal transplant" por entender primeiro que a ideia de transplante, por não ser mecânica como é a transferência de normas jurídicas (em oposição à biologia e sua necessidade de "implantação e cultivação no meio ambiente"), não funciona. Também porque, segundo ele, a ideia de transplante traz implícita a assunção de que, uma vez feito o procedimento, o material transplantado funcionaria identicamente, e tão bem, como funcionava no antigo organismo, no novo ${ }^{14}$. E por ser dessa forma, não haveria como se sair da seguinte constatação: ou haveria a repulsa total ou a aceitação total do transplante.

Para Teubner não acontece um transplante, mas uma 'irritação', que propicia novos e inesperados eventos (irritação cultural e irritação, principalmente, de arranjos institucionais). Para ele, o que existe "é um barulho externo que cria perturbações selvagens no jogo de discursos dentro desses arranjos e os força a reconstruir internamente não só suas próprias regras mas a reconstrui-las a partir do arranhão do próprio elemento externo.”15

Maximo Langer publicou influentes artigos de direito processual penal comparado nos quais trata de duas vertentes que são pertinentes ao direito comparado e a este estudo.

Na primeira vertente ele defende a ideia de "traduções" (não, portanto, transferências ou empréstimos ou irritantes ou transplantes

12 Ibidem, p. 6.

13 Não parece ter sido o principal foco do texto do professor da London School of Economics, mas não passa despercebida a lembrança que ele faz de Montesquieu e de que sempre esteve no âmago do estudo do direito comparado a relação entre os atualmente chamados "países desenvolvidos" e "países em desenvolvimento" (KAHN-FREUND, Otto. On uses and misuses of comparative law. The Modern Law Review, v. 37, n. 1, p. 1-27, jan. 1974. p. 8).

14 TEUBNER, Gunther. Legal Irritants: good Faith in British Law or How Unifying Law Ends up in New Divergences. The Modern Law Review, vol. 61, n. 1, p. 11-32, jan. 1998. p. 12.

15 Ibidem, p. 12. 
como signos do aproveitamento de regras jurídicas de um país por outro). $\mathrm{Na}$ segunda vertente assume a perspectiva não de neocolonialismo ou imperialismo ${ }^{16}$ inerente à tal "tradução", mas, no cenário do processo penal latino americano, de difusão de ideias da chamada "periferia" como as que justificam as mudanças ocorridas em vários sistemas processuais penais pelo menos a partir da década de 80 do século XX.

Na primeira perspectiva, o ponto de partida de Langer é que a difusão do termo "transplantes" é errada porque o próprio termo significa um mero "recorta e cola" ${ }^{17}$ entre os sistemas jurídicos em comparação. A "tradução", na longa e profunda abordagem do autor, ao invés do transplante, significaria um método mais heurístico para a abordagem da “circulação de ideias, regras, práticas e instituições jurídicas”18.

Segundo Maximo Langer, "a metáfora da tradução retém a dimensão comparativa que fez com que a metáfora do transplante fosse tão poderosa e que falta na metáfora do 'legal irritant'. Com relação aos sistemas jurídicos, a metáfora da tradução distingue a fonte linguística ou sistema jurídico - de onde vem a ideia ou a instituição - do sistema de destino - na qual a ideia jurídica ou instituição é traduzida. A metáfora da tradução também permite a distinção a ser feita entre o 'texto'

16 LANGER, Maximo. Revolution in Latin American Criminal Procedure: Diffusion of Legal Ideas from the Periphery. The American Journal of Comparative Law, v. 55, n. 4, p. 617-676, 2007. p. 621.

17 Um autêntico "cut and paste" (LANGER, Maximo. From Legal Transplants to Legal Translations: The Globalization of Plea Bargaining and the Americanization Thesis in Criminal Procedure. Harvard International Law Journal, v. 45, n. 1, p. 1-64, 2004. p. 5).

18 LANGER, Maximo. From Legal Transplants to Legal Translations: The Globalization of Plea Bargaining and the Americanization Thesis in Criminal Procedure. Harvard International Law Journal, v. 45, n. 1, p. 1-64, 2004. p. 32. Langer também critica a expressão de Teubner, vista acima, basicamente porque o "irritante" não vem necessariamente de fora, ou seja: do ponto de vista do direito comparado, a metáfora nem serve. Lena Fojanty também trata das várias metáforas do que aqui se estuda em direito comparado (transplante, irritante, tradução, circulação, transferência, migração, circulação, amálgama, hibridização, creolização, viagem, adaptação) e desenvolve seu texto pela preferência da metáfora da tradução (FOLJANTY, Lena. Legal Transfers as Processes of Cultural Translation: On the Consequences of a Metaphor., p. 1-18). 
original - a ideia ou instituição tal qual desenvolvida no sistema jurídico de fonte - e o texto traduzido." 19

Noutra perspectiva, mas não menos importante do ponto de vista da assimilação de mudanças legislativas com arrimo em direito comparado, Langer volta a se debruçar sobre a assimilação pelos países da América Latina de certa "americanização" dos vários sistemas processuais penais. Ali, conquanto a premissa sociológica seja o tratamento dos Estados ora como "central" e os países latino-americanos como "periféricos" (distinção fértil trazida por outros autores, como por exemplo, Jorge L. Esquirol e Daniel Bonilla Maldonado, dos quais se tratará abaixo, não se valendo da expressão de centro e periferia, mas de "norte" e "sul"), foi proposta a irradiação de modificações legislativas não a partir de emulação por parte dos periféricos, das normas advindas do país central (EUA) ${ }^{20}$.

O texto se espalha por intrincadas redes imaginadas pelo autor, em que as difusões de ideias jurídicas não são sempre verticalizadas (no modelo impositivo, "de cima para baixo") e nem horizontalizadas (em situações de plena igualdade de condições para o transporte de ideias jurídicas de um a outro país), mas chegam ao ponto de ser triangulares ${ }^{21}$.

A exposição passa por abordagem de grupos de ativistas latino-americanos ${ }^{22}$ que se fizeram responsáveis seja pela recepção, seja pela crítica, aos ideais norte-americanos conformadores do processo penal (e consequentemente, das pretendidas e difundidas alterações nos países da América Latina).

Langer não trabalha com a ideia consagrada de 'transplante' e nem concorda com a crítica difundida por autores como Jorge L. Esquirol,

19 LANGER, Maximo. From Legal Transplants to Legal Translations: The Globalization of Plea Bargaining and the Americanization Thesis in Criminal Procedure. Harvard International Law Journal, v. 45, n. 1, p. 1-64, 2004. p. 33.

20 Ibidem, p. 62.

21 LANGER, Maximo. Revolution in Latin American Criminal Procedure: Diffusion of Legal Ideas from the Periphery. The American Journal of Comparative Law, v. 55, n. 4, p. 617-676, 2007. p. 624-625.

22 Só para citar dois processualistas penais vivos, Julio Maier e Alberto Binder (LANGER, Maximo. Revolution in Latin American Criminal Procedure: Diffusion of Legal Ideas from the Periphery. The American Journal of Comparative Law, v. 55, n. 4, p. 617-676, 2007. p. 645). 
Ugo Mattei e Daniel Maldonado, de que - observadas as distinções peculiares do desenvolvimento de cada contribuição autoral - o que se deu no contexto latino-americano seria reduzido a uma "americanização" dos sistemas processuais penais, a partir dos anos 80 do século passado.

Nos seus textos não se nota grande importância às coincidências entre o fortalecimento de Estados Democráticos de Direito na América Latina e maciços investimentos de entidades multinacionais públicas ou privadas como ONU, OEA, BIRD, Banco Mundial e USAID.

A análise de Langer caminha por outros rumos, seja privilegiando a noção de 'tradução' ao invés da de 'transplante', seja - sem fechar os olhos às influências ocorridas sob várias formas do país chamado de central (EUA) aos periféricos da América Latina - por privilegiar a rede de cientistas e ativistas que dialogaram, com aceitação ou resistência, na metáfora de rede triangular que ele explora.

David Nelken trata das metáforas sob viés que, além de reforçar a sua utilidade didática, possibilita a continuidade da abordagem, chegando mais perto do que aqui se propõe a fazer, que é responder à pergunta: $e$ depois dos transplantes?

O autor inicialmente aproxima conceitualmente os 'transplantes' jurídicos das 'transferências' jurídicas ("legal transfers”) 23, depois separa os conceitos para preferir a última expressão ${ }^{24}$ e então se pergunta sobre os critérios válidos para se aferir se determinada transferência jurídica (ou transplante) é ou não exitosa(o), se teve ou não sucesso no país de destino. Afinal, o "sucesso de um ponto de vista não necessariamente implica o sucesso de outro. O que nós testemunhamos, quando mudança legal não leva a uma mudança social, é um conjunto radiante de eventos intencionais e não intencionais" 25

É a partir do enfoque de David Nelken que se pode chegar ao passo seguinte, qual seja, pensar no que acontece depois dos transplantes

23 NELKEN, David. The Meaning of Success in Transnational Legal Transfers. 19 Windsor Yearbook of Access to Justice, p. 349-66, 2001. p. 349.

24 NELKEN, David. Comparatists and transferability. In: LEGRAND, Pierre; MUNDAY, Rodrick (Eds.) Comparative Legal Studies: Traditions and Transitions. Cambridge: Cambridge University Press, 2003. p. 463-464.

25 NELKEN, David. The Meaning of Success in Transnational Legal Transfers. 19 Windsor Yearbook of Access to Justice, p. 349-66, 2001. p. 351. 
jurídicos ou transferências. Afinal, como é particularmente pertinente em se tratando de transferências jurídicas, "a lei não só tem um social contexto, mas ela também faz um contexto" ${ }^{26}$.

E como lembra Elisabetta Grande, o arranjo jurídico preexistente no país de destino da alteração legislativa pode ser de fato anulado, modificado, distorcido, remodelado, ou mesmo fazer brotar algo novo a partir do modelo original que, por sua vez, pode receber uma influência devolutiva, no contexto de sua produção original. Por isso é que se chega a trabalhar até mesmo com a ideia de "contaminação" entre os sistemas jurídicos, e não só com "transplante", transferência. ${ }^{27}$

Nesse particular é que Nelken repete as preocupações que devem ser parte integrante do diagnóstico do 'sucesso' das transferências jurídicas. Dentro de tantas questões que imbricam com o resultado exitoso ou não dessas transferências, devem contar, "da mesma maneira que mudanças sociais por intermédio de leis em contextos nacionais dependem do que está sendo transferido, por qual fonte, o caminho pelo qual a transferência é introduzida, o número de grupos sociais envolvidos, e um número potencialmente ilimitado de amplos fatores de retaguarda e experiências históricas prévias." 28 .

O fato é que o transplante, ou a tradução, não se faz só com porretes ou tanques, mas também com sedutores discursos e incentivos financeiros, seja do ponto de vista explícito, seja do ponto de vista da

26 NELKEN, David. Comparatists and transferability. In: LEGRAND, Pierre; MUNDAY, Rodrick (Eds.) Comparative Legal Studies: Traditions and Transitions. Cambridge: Cambridge University Press, 2003. p. 452.

27 GRANDE, Elisabetta. Legal Transplants and the inoculation effect. How American criminal procedure has affected continental Europe. The American Journal of Comparative Law, v. 64, p. 583-618, 2016. p. 586.

28 NELKEN, David. Comparatists and transferability. In: LEGRAND, Pierre; MUNDAY, Rodrick (Eds.). Comparative Legal Studies: Traditions and Transitions. Cambridge: Cambridge University Press, 2003. p. 454. Há inúmeras perguntas que tornam essa valoração do sucesso e da falha no transplante (ou na transferência) particularmente complexa. Assim: "o que nós entendemos por 'sucesso'? quais são as condições que fazem as transferências jurídicas menos ou mais exitosas? Outros problemas conceituais têm relação com quem tem (e quem deve ter) o poder de definir sucesso. Colocado de maneira diferente, de quem são os interesses que contam? Aqueles dos países que 'exportam' lei ou dos países que a 'recebem'? (Ibidem, p. 453-4). 
própria formação intelectual - e curricular - da elite jurídica de cada país. As nuances de uma ou outra constatação, as asas críticas de cada autor na abordagem disso, fazem com que as influências possam ser vistas como mais ou menos determinantes.

Por isso, não importam só as metáforas, mas em que elas se embasam (por que afinal, há transplantes jurídicos, ou ao menos, nos tempos que importam para um estudo de alteração no processo penal brasileiro, transplantes jurídicos recentes?), e a que elas se prestam (o que se faz depois dos transplantes, nos países que têm seus sistemas ou suas regras jurídicas alteradas a partir do modelo estrangeiro?.). ${ }^{29}$

\section{As MEtÁforAs: O 'ANTES' E O 'DEPOIS'}

Segundo Michele Graziadei, o estudo de transplantes e recepções deve focar primordialmente em três fatores: imposição de lei por meio de violência; mudança produzida pelo desejo de seguir modelos de maior prestígio; e finalmente, reformas com vistas à melhora de situação econômica ${ }^{30}$.

O primeiro dos fatores é de fácil exemplificação e, na visão do autor, pode ser bem percebido com conquistas e expansões militares antigas ou recentes, como a Anschluss de 1938, em que a Alemanha estendeu as fronteiras até a Áustria, ou mesmo as mimetizações de países formalmente colonizados na América (Latina, majoritariamente), África ou Ásia. ${ }^{31} \mathrm{O}$ segundo e o terceiro, por serem mais atuais e por chegarem mais perto do contexto inclusive geográfico da América Latina, e que desaguam no direito processual penal, merecem estudo mais agudo.

29 Elisabetta Grande lembra ainda de outras metáforas utilizadas, como "fluxo”, “circulação”, “importação/exportação jurídica”, “migração”. (GRANDE, Elisabetta. Legal Transplants and the inoculation effect. How American criminal procedure has affected continental Europe. The American Journal of Comparative Law, v. 64, p. 583-618, 2016. p. 585)

30 GRAZIADEI. Michele. Comparative Law as the Study of Transplants and Receptions. In: REINMANN, Mathias; ZIMMERMANN, Reinhard (eds.). The Oxford Handbook of Comparative Law. Oxford: Oxford University Press, 2006. p. 456.

31 Ibidem, p. 456. 
O fator prestígio ("prestige") se associa à retórica do desejo ("desire”) para, sem violência, seduzir os países destinatários para imitarem as regras jurídicas dos países que as 'transferem'. Diz Graziadei, a propósito: "Portanto, prestígio motiva imitação.” ${ }^{32}$ Prestígio, de um lado, e desejo, de outro, são palavras utilizadas por Michele Graziadei que, talvez sem que o próprio autor tenha percebido, possam se complementar.

O "prestígio" pode ser utilizado atualmente como parte do discurso que polariza a respeitabilidade (tácita) dos estudos (ergo, das regras jurídicas) que vêm do chamado "Norte". A esse "prestígio" se associa a antípoda ("desprestígio") dos estudos e das regras jurídicas do "Sul”.

Nessa equação, há, a partir do prestígio (vale frisar que o olhar "de onde vem" o prestígio é um olhar do Sul voltado para o Norte, exemplificativamente da América Latina voltada para a Europa ou para os Estados Unidos; da USP, das PUCs, das FGVs voltados para Yale, Columbia, Humboldt, Sorbonne, Complutense, La Sapienza etc) uma tácita distinção que patrocina a separação entre o que é aprioristicamente melhor do aprioristicamente pior.

O que vem do Norte global é quase uma grife, na lembrança trazida por Daniel Bonilla Maldonado: "Como um vinho da Borgonha é considerado um bom vinho, um artigo escrito em inglês por um professor americano e publicado em um jornal jurídico em uma universidade da América do Norte é considerado como de boa qualidade, mesmo antes de ser lido. O conhecimento jurídico gerado no Sul só é legitimado quando acadêmicos do Norte tenham dado a ele a sua aprovação. Os produtos jurídicos do Sul são marcados (negativamente) por sua origem"33

32 Ibidem, p. 458. Ver também: MATTEI, Ugo. A theory of imperial law: a study on U.S. hegemony and the latin resistance. Indiana Journal of Global Legal Studies, vol. 10, n. 1, p. 382-448, 2003. p. 385. Com ampla bibliografia específica: GRANDE, Elisabetta. Legal Transplants and the inoculation effect. How American criminal procedure has affected continental Europe. The American Journal of Comparative Law, v. 64, p. 583-618, 2016. p. 586, rodapé 13.

33 MALDONADO, Daniel Bonilla. Constitucionalism of the Global South. The Activist Tribunals of India, South Africa, and Colombia. Cambridge: Cambridge University Press, 2013. p. 12. Wolfgang Weigand desenvolve arguta análise sobre a difusão de modelos de ensino jurídico e de alterações jurídicas vindas dos Estados Unidos, não para América Latina, mas propriamente para países europeus (WEIGAND, Wolfgang. Americanization of Law: Reception or 
Abaixo se tratará da retórica do "prestígio" e da exportação quase que intuitiva (afinal, o que é do Norte é melhor do que o que é do Sul) do modelo de rule of law. Por enquanto, para complementar a equação "prestígio" e "desejo", se o diagnóstico já está feito ${ }^{34}$, a melhor forma de se trazer o que "há de melhor" para o país de destino costuma ser identificada com a ideia de transplante. A crítica ao resultado do conteúdo obtido fora do país, além de abertamente propiciar debates que extravasam esse texto, não desnatura esse diagnóstico.

Claro que o prestígio possui, portanto, a força catalisadora de ser um produto de exportação (e importação) das ideias jurídicas. E, no trânsito de pessoas e ideias, é desejável (alguém até dirá ser inclusive juridicamente legítimo) que as melhores ideias sejam trazidas para os países (em desenvolvimento) que delas necessitam. Afinal, discursivamente, o conhecimento é para ser difundido, e a vanguarda científica não pode ser privilégio de poucos ${ }^{35}$.

Por isso, sim, prestígio é fonte de desejo, e nessa equação há a exportação de ideias jurídicas. No contexto latinoamericano, esse discurso

Convergence? In: FRIEDMAN, Lawrence M.; SCHEIBER, Harry N. (eds.) Legal Culture and the Legal Profession, Bouldere: Westview Press, 1996. p. 137152). Bernd Schüneman trata criticamente do que ele nomeia como "marcha triunfal do modelo processual norte-americano sobre o mundo" (SCHÜNEMAN, Bernd. Um olhar crítico ao modelo processual penal norte-Americano- In: SCHÜNEMAN, Bernd; GRECO, Luís (coord.). Estudos de direito penal, direito processual penal e filosofia do direito. Marcial Pons: Madri, Barcelona, Buenos Aires. São Paulo. 2013, p. 240-261).

34 Onde estão as melhores universidades? Onde estão os melhores professores? As melhores bibliotecas? Qual estudante latinoamericano, enfim, que queira se destacar como cientista não pretende se vincular às mais prestigiadas universidades? Não é essa, em boa medida, a ideia de "bolsas-sanduíche", ao menos no Brasil?

35 O problema dessa afirmação com vocação universal é que, como lembra acidamente Esquirol, "as opiniões provenientes dos centros de poder podem induzir uma espécie de internalização de ideias que logo se convertem em verdades por essa mesma razão. Os estudados podem acabar se vendo através dos olhos de seus observadores.” Páginas adiante, "esta apreensão se expressa na preocupação de que os latinoamericanos tenham que se converter em 'latinoamericanistas' se querem ser ouvidos no Norte." (ESQUIROL, Jorge L. El nuevo latinoamericanismo jurídico. In: BONILLA MALDONADO, Daniel (org.). Geopolítica del conocimiento jurídico. Bogotá: Siglo del Hombre Editores, 2015. p. 306 e 326). 
globalizante que separa o "Norte" do "Sul" em termos de merecimento de influência (hierarquiza as fontes do conhecimento) ainda ganhou novo combustível com o diagnóstico de que, genericamente se olha para o sistema jurídico latinoamericano como "falido"36.

Do ponto de vista geopolítico e de expansão e consolidação das ideias aprioristicamente mais bem formuladas (do Norte), nem seria necessário o recurso retórico ao "failed law" que se difundiu como epíteto de todo o regime jurídico latinoamericano, tão vigorosamente denunciado por Jorge L. Esquirol.

De toda forma, ainda assim, as metáforas de "failed law" (corrupção endêmica, sociedade não responsiva às leis - baixa correspondência entre law in action e law in the books-, insegurança jurídica e social, inoperância, ineficiência, elitismo jurídico) se constituíram como importante discurso facilitador de projetos de reformas jurídicas ${ }^{37}$.

A abordagem de Esquirol é profunda e extensa. Uma das perspectivas que ela possibilita atingir é que, se a imagem de "direito falido ${ }^{38}$ ", como diz ele, "fornece uma lógica convincente para reconfigurar arranjos existentes" 39 , a hiperbólica fragilidade descrita das instituições jurídicas latinoamericanas como um todo realmente as denigrem ao ponto de, assemelhando-as às "repúblicas-de-bananas", tornarem no limite inevitável que os transplantes jurídicos aconteçam. O diagnóstico construído é o de terra arrasada ${ }^{40}$.

36 ESQUIROL, Jorge L. The Failed Law of Latin America. The American Journal of Comparative Law, v. 56. n. 1, p. 75-124, 2008. p. 75-124. Também: Las ficciones del derecho latinoamericano. Bogotá: Siglo del hombre editores. Universidad de los Andes, 2014.

37 ESQUIROL, Jorge L. The Failed Law of Latin America. The American Journal of Comparative Law, v. 56. n. 1, p. 75-124, 2008. p. 76.

38 Tradução livre para "failed law".

39 ESQUIROL, Jorge L. The Failed Law of Latin America. The American Journal of Comparative Law, v. 56. n. 1, p. 75-124, 2008. p. 78.

40 Esse diagnóstico não é tão central ao que se propõe a fazer neste trabalho, mas a "terra arrasada" como entendemos se associa à ideia de "república-de-bananas" como algo que, na origem (failed law) clama por reformas. Acontece que essas próprias reformas, ao mudarem completamente os sistemas jurídicos a partir da premissa de que nada presta, acaba por deixar as repúblicas ainda mais fragilizadas, sem qualquer autoestima suficiente para que elas mesmas atinjam as soluções e evoluam no sentido de 'alcançarem' o Estado de Direito 
Outra perspectiva, que dialoga com o dístico "prestígio-desejo' é obviamente esta: no diagnóstico do "direito falido", o que há é o desprestígio, a baixa-estima, a incredulidade genericamente (e por isso, artificial, diz Esquirol ${ }^{41}$ ) construída do sistema jurídico da América Latina. Isso também catapulta o desejo de troca das estruturas jurídicas ${ }^{42}$, senão como um todo, ao menos em grande parte. O campo, pois, é fértil para a recepção dos transplantes jurídicos.

Nas palavras de Esquirol: "Significativamente, os transplantes jurídicos não são novos na América Latina. Eles são entendidos como parte de uma conexão histórica entre América Latina e Europa, e atualmente os Estados Unidos, e refletem a suposta qualidade e prestígio desses sistemas doadores. É, portanto, bem aceito que o direito positivo da região mergulha em várias fontes da Europa Ocidental e da América do Norte.” ${ }^{43}$

O terceiro fator motivador recente de transplantes jurídicos se reduz ao movimento do law and development. Nas palavras de Graziadei, isso se resume à "relação entre performance econômica e instituições jurídicas.”. ${ }^{44}$

que vem com as ideias de fora. Por isso, para Esquirol, e em resumidíssima síntese: os Estados latinoamericanos ficam ainda mais fracos juridicamente, mais dependentes das reformas, a partir delas mesmas. Para uma postura menos radical, mas crítica quanto ao discurso de se implementar o Estado de Direito em países latino-americanos por meio de transplantes jurídicos vindos de regras do processo penal norte-americano (sobretudo em matéria de negociação de pena), ver: ANITUA, Gabriel Ignacio. La Importación de Mecanismos Consensuales del Proceso Estadounidense, en las Reformas Procesales latinoamericanas. Revista Brasileira de Direito Processual Penal, Porto Alegre, vol. 1, n. 1, p. 43-65.

ESQUIROL, Jorge L. The Failed Law of Latin America. The American Journal of Comparative Law, v. 56. n. 1, p. 75-124, 2008. p. 84 e ss.

42 "As regras do jogo na América Latina incluíram o próprio jogo na questão." (ESQUIROL, Jorge L. The Failed Law of Latin America. The American Journal of Comparative Law, v. 56. n. 1, p. 75-124, 2008. p. 79)

43 ESQUIROL, Jorge L. The Failed Law of Latin America. The American Journal of Comparative Law, v. 56. n. 1, p. 75-124, 2008. p. 96.

44 GRAZIADEI. Michele. Comparative Law as the Study of Transplants and Receptions. In: REINMANN, Mathias; ZIMMERMANN, Reinhard (eds.). The Oxford Handbook of Comparative Law. Oxford: Oxford University Press, 2006. p. 459. 
A imbricação entre direito e economia, originariamente já complexa do ponto de vista político a partir do surgimento da teoria do law and economics na Guerra Fria, quando a prosperidade econômica era atrelada à estabilidade jurídica e, por isso, justificava o transplante jurídico inclusive para se debelar o risco de 'contágio' de ideias comunistas ${ }^{45}$, ganhou ainda maior destaque nos idos dos anos 80 e 90 do século passado.

Isso porque, enraizada na exploração política e jurídica da exportação de modelo capitalista que "vendia" prosperidade econômica como sinônimo de tranquilidade jurídica e rule of law (por isso, Esquirol rotulava o resultado da law and economics para América Latina como consolidação de uma 'U.S.sphere'46), naqueles últimos anos não só países como instituições financeiras internacionais promoveram, nas palavras de Graziadei, "um dos mais ambiciosos programas de reforma jurídica nas últimas décadas" ${ }^{7}$.

O que se pode dizer, então, desse último fator, é que, inicialmente, a transposição de sistemas jurídicos foi ostensiva, de país para país, mas desde os anos 80 o transplante sequer passou a ser feito ostensivamente a partir de ideias consagradas em países isolados, mas sim de ideário consagrado multilateralmente e de forma não mais diretamente atrelada a um

45 Esse "risco" se imaginava debelado com a exportação de prosperidade econômica, ou seja: redução da pobreza. The failed law..., cit., p. 90. Em texto recentemente traduzido, Eric Hobsbawn diagnosticou que "os imperialistas menos ideológicos estavam, em teoria (de acordo com a "doutrina Mann" da era Lyndon B. Johnson), contentes com qualquer pessoa que promovesse o crescimento econômico, protegesse os investimentos privados e se opusesse ao comunismo, independentemente da atitude em relação às reformas sociais. (...) O novo pragmatismo confortava-se $\mathrm{cm}$ a crença de que a estabilidade econômica e o crescimento resolveriam automaticamente os problemas sociais, enquanto um militar pago, treinado e inspirado pelos Estados Unidos deveria ser, em algum sentido metafísico, "constitucionalista”, se não realmente democrático.” (HOBSBAWN, Eric. Viva la Revolución. A era das utopias na américa latina. Trad. Pedro Maia Soares. São Paulo: Companhia das Letras, 2017. p. 348)

46 ESQUIROL, Jorge L. The Failed Law of Latin America. The American Journal of Comparative Law, v. 56. n. 1, p. 75-124, 2008. p. 89.

47 GRAZIADEI. Michele. Comparative Law as the Study of Transplants and Receptions. In: REINMANN, Mathias; ZIMMERMANN, Reinhard (eds.). The Oxford Handbook of Comparative Law. Oxford: Oxford University Press, 2006. p. 459. 
determinado país, seja em organizações multilaterais como a Organização dos Estados Americanos, seja em agências de fomento. E as últimas poderiam, ou não, estar ligadas a um determinado Estado, como foi o caso da USAID $^{48}$, mas não foi o caso de Banco Mundial e Banco Interamericano de Desenvolvimento, nem do Fundo Monetário Internacional ${ }^{49}$.

Do ponto de vista do desenvolvimento da ciência do direito comparado, nem essa desterritorialização (ou desnacionalização) passa despercebida. Como ressalta Ugo Mattei, "o direito comparado tradicional é prisioneiro de um paradigma territorial nacional de indagação que está moribundo como uma ferramenta de se entender a globalização jurídica. Portanto, par que o comparativista se torne um advogado global efetivo, é necessário repensar a ideia moderna de fronteiras. As ferramentas devem ser inventadas para comparar sistemas jurídicos não-territoriais entre eles mesmos assim como com os territoriais." ${ }^{50}$

O que se pode antecipar como conclusão aqui é que as metáforas utilizadas, sejam quais forem, são tão operativas, isto é, tão instrumentais, quanto o próprio fenômeno que elas pretendem descrever (transplante, transferência etc.). A engrenagem jurídica, em si mesma, não existe à toa, e não existe despida de interesses que a movem num ou noutro sentido.

48 United States Agency for International Development. Maximo Langer contextualiza a criação dessa agência: o ano é 1961, o presidente é John F. Kennedy, o contexto é a guerra fria e o objetivo é espalhar desenvolvimento econômico para diminuir o risco de grupos comunistas ou de esquerda assumirem o poder em países em desenvolvimento. Esse foi o pontapé inicial do USAID e a política reformista norteamericana endereçada aos países latinoamericanos. Houve hiato entre as décadas de 70 e 80 do século passado e, de $1985 \mathrm{em}$ diante, o USAID voltou a promover cursos voltados à reforma processual latinoamericana e se mostrar influente em diversos países. (LANGER, Maximo. Revolution in Latin American Criminal Procedure: Diffusion of Legal Ideas from the Periphery. The American Journal of Comparative Law, v. 55, n. 4, p. 617-676, 2007. p. 646-650).

Ver: MALDONADO, Daniel Bonilla. Introducción. Teoria del Derecho y Transplantes Juídicos: la estrutura del debate. In Teoria del Derecho y transplantes jurídicos. Daniel Bonilla Maldonado. Editor académico. Siglo del Hombre Editores. Universidade de los Andes. Pontifícia Universidad Javeriana. 2009, p.12-3.

50 MATTEI, Ugo. A theory of imperial law: a study on U.S. hegemony and the Latin resistance. Indiana Journal of Global Legal Studies, vol. 10, n. 1, p. 382448, 2003. p. 413. 
Atualmente, em que a discussão geopolítica específica da América Latina chama a atenção - mesmo para autores que se desviam por escolha metodológica desse pedaço do problema, como é o caso de Máximo Langer - pode-se ser mais radical, como Esquirol, Bonilla Maldonado e Ugo Mattei, ou menos, como David Nelken.

De qualquer forma, como menos importa a carga autoral do que a verificação da pretensão normativa dos transplantes, não há como se fechar os olhos seja para a desterritorialização da "origem" das normas jurídicas, seja (o mais importante) para a pretensão uniformizadora, vinda dos Estados Unidos, em direção aos países da América Latina, inclusive o Brasil.

Se isso significa uma "americanização" do direito processual penal ou, na linguagem de Elisabetta Grande (em outra metáfora de biologia), uma "inoculação" ${ }^{1}$ contra a expansão do modelo norteamericano de processo penal, além de motivar outra discussão, para este texto cabe bem na medida em que se está outra vez questionando o que vem depois dos transplantes jurídicos.

Como frisa Nelken, com base nas constatações vistas neste texto, “o que está realmente sendo exportado no presente momento dos transplantes jurídicos, junto a qualquer dada instituição ou procedimento jurídico, é uma ideologia cultural específica." ${ }^{52}$

51 No texto aqui já referido a professora italiana nada contra a corrente dos estudiosos que veem na propalada difusão das ideias de processo penal norteamericano (via transplantes jurídicos) a americanização do processo penal. Para ela, a própria ideia de transplantes, no caso, gera a ideia de inoculação, e a metáfora da biologia (mais uma...) é esta: "Inoculação é a injeção de uma porção pequena de um organismo em um corpo, estimulando a produção de anticorpos que - pela imunização do corpo contra o organismo injetado - previne da maior difusão daquele mesmo organismo no futuro. Pelo mesmo símbolo, eu irei argumentar, a injeção de dose pequena de características jurídicas adversariais nos sistemas processuais da Europa Continental fortaleceu a estrutura não-adversarial, e por isso parece ter produzido "anticorpos" capazes de fazê-los resistentes contra qualquer difusão futura de um processo adversarial nos seus corpos jurídicos." (GRANDE, Elisabetta. Legal Transplants and the inoculation effect. How American criminal procedure has affected continental Europe. The American Journal of Comparative Law, v. 64, p. 583-618, 2016. p. 584)

52 NELKEN, David. Comparatists and transferability. In: LEGRAND, Pierre; MUNDAY, Rodrick (Eds.). Comparative Legal Studies: Traditions and Transitions. Cambridge: Cambridge University Press, 2003. p. 458. Também assim: 
Diagnosticado o "antes", isto é, o motivo ideológico dos transplantes, vamos ao "depois". A principal pergunta que se faz aqui é se o "modelo" ou a regra importada "cabe" nos sistemas de destino, isto é, se ela é talhada para o sistema ou, em termos mais próximos do direito comparado, se deve ser exigida alguma semelhança entre os sistemas para que o transplante seja exitoso.

\section{Depois dos transplantes: o falso problema do cabimento NA ANÁLISE DO SUCESSO}

As noções de sucesso e falha são inerentes à polarização discursiva que permeia em boa medida a abordagem dos transplantes jurídicos. Pergunta-se se o transplante foi exitoso ou se fracassou. Normalmente tal questionamento se prende aos tradicionalismos do país de destino, à história, ao "modelo" consagrado, à reação social ao transplante. Enfim, na continuidade da metáfora: se o novo órgão inserido no corpo velho é "aceito".

Acima já se falou da abordagem de Nelken, segundo quem e em linguagem aqui resumida, o que é exitoso para uns pode ser um fracasso para outros (na verdade, essa própria ponderação é uma das por ele utilizadas para rechaçar a metáfora de transplante). Como também se lembrou de Elisabetta Grande, segundo quem o próprio efeito do transplante pode não atingir só o Estado que recebe determinadas normas jurídicas, mas também o Estado de onde elas têm sua origem (e por isso ela lembrou da metáfora de circulação de modelos).

O 'efeito' ou 'sucesso' dos transplantes pode ser apreciado sob outra perspectiva, para além daquela puramente atrelada às consequências das modificações jurídicas nos países que 'recebem' determinadas normas jurídicas. A adoção de modelos jurídicos diversos - os transplantes jurídicos - pode ser criticada sob o prisma do seu cabimento. Singelamente, afinal, o determinado transplante "cabe" num determinado sistema? E, nesse particular, essa é uma pergunta relevante do ponto de vista do direito comparado?

GRANDE, Elisabetta. Legal Transplants and the inoculation effect. How American criminal procedure has affected continental Europe. The American Journal of Comparative Law, v. 64, p. 583-618, 2016. p. 586. 
Há, segundo Nelken, duas perspectivas sob as quais o cabimento pode ser visto, e ambas arrancam a raiz na falibilidade da aderência social das leis. Por um lado, a mera constatação de que a sociedade nem sempre se adequa ao que prega a lei faz com que o cabimento do transplante não passe de um falso problema. Por outro lado, o cabimento da alteração vinda via transplante é sim relevante para se pensar no depois do transplante, na medida em que - justamente por haver dessintonia com frequência entre lei e sociedade - o novo modelo jurídico pode significar uma desejada alteração social, política ou econômica. Pode significar, enfim, um plano de transformação da própria sociedade. ${ }^{53}$

O 'sucesso' ou a 'falha' dos transplantes jurídicos não estão pura e simplesmente no "cabimento" do modelo exportado em determinado modelo de destino. Não há uma relação necessária entre causa (cabimento) e efeito (sucesso ou não) no que aqui se estuda. É importante reconhecer isso: "ao invés objetivar a reprodução de condições passadas ou presentes ou ideais, a lei objetiva superá-las." ${ }^{4}$

A lei e sua relação com o país de destino, portanto, não deve necessariamente ser de cabimento; ela não tem que caber em determinado sistema de destino. O equacionamento do sucesso ou não de determinado transplante jurídico a partir da análise de seu cabimento no sistema de destino, diz Michele Graziadei, distorce a realidade, é pautado por generalizações que (por serem generalizações) deixam de analisar o próprio transplante efetuado e, inclusive, desconsideram os atores (e, assim, também os próprios interesses) que participam do procedimento de transplante ${ }^{55}$.

A ideia mesma do transplante é a alteração do próprio sistema, e é disso que se cuidou acima, com tons mais ou menos críticos a depender da abordagem de cada autor. Nesse sentido, “a apropriação de elementos

53 NELKEN, David. Comparatists and transferability. In: LEGRAND, Pierre; MUNDAY, Rodrick (Eds.). Comparative Legal Studies: Traditions and Transitions. Cambridge: Cambridge University Press, 2003. p. 451.

54 Ibidem, p. 457.

55 GRAZIADEI. Michele. Comparative Law as the Study of Transplants and Receptions. In: REINMANN, Mathias; ZIMMERMANN, Reinhard (eds.). The Oxford Handbook of Comparative Law. Oxford: Oxford University Press, 2006. p. 472-3. 
estrangeiros pode ser disfarçada por vesti-los em roupas familiares." ${ }^{56}$ No ponto em que se chega ao processo penal, vem a elegante passagem de Mirjan Damaška: "a música da lei muda, assim dizendo, quando os instrumentos musicais e os músicos não são mais os mesmos." 57

O ponto, portanto, para se verificar o sucesso ou não do transplante, não é se ele cabe ou não no sistema de destino. Novamente com Nelken, "o que faz uma boa tradução é sua fidelidade aos mundos diferentes ao invés de seus efeitos ou consequências." ${ }^{8}$ Se o modelo cabe ou não, portanto, não é um problema de direito comparado, que por si só seria impeditivo de se realizar o transplante jurídico.

Se isso pode ser tomado cientificamente como plausível, onde estaria o problema?

Com isso, chega-se ao processo penal brasileiro, a partir do diagnóstico do pastiche e da falta de racionalidade - tanto em termos do que se escolhe como modelo, seja em termos de sua extensão, quanto principalmente em termos da total despreocupação com seu funcionamento no país de origem e cálculo consequencialista - que tem guiado o mimetismo de institutos para serem transplantados para cá.

Do que se cuidará abaixo, depois dos transplantes jurídicos, não é de acomodação sistemática, mas sim do seu retalhamento, que aqui se pode dizer assistemático. O problema com o qual o direito processual penal brasileiro se defronta atualmente é o da irracionalidade dos critérios que tem seguido para se valer dos transplantes jurídicos.

\section{Processo penal brasileiro atual à luz do direito COMPARADO: UM PASTICHE LEGAL}

A expressão crítica que resume o diagnóstico que parece ser aplicável ao cenário atual brasileiro é cunhada por Mirjan Damaška. O "legal

56 Ibidem, p. 462.

57 DAMAŠKA, Mirjan. The uncertain fate of evidentiary transplants: Anglo-American and Continental Experiments. The American Journal of Comparative Law, v. 45, n. 4, p. 839-852, 1997. p. 840.

58 NELKEN, David. The Meaning of Success in Transnational Legal Transfers. 19 Windsor Yearbook of Access to Justice, p. 349-66, 2001. p. 361. 
pastiche", segundo o ponto de vista com o qual aqui se concorda é o produto do seguinte procedimento: "na busca pela inspiração por mudança, é talvez natural para advogados navegar numa boutique de lei estrangeira. Mas é uma ilusão pensar que essa é uma boutique na qual alguém é sempre livre par adquirir alguns itens e rejeitar outros. Um arranjo decorrente de uma aquisição parcial - um pastiche legal - pode produzir um resultado de investigação bem menos satisfatório na prática do que sob ou arranjos probatórios continentais ou Anglo Americanos em sua forma não adulterada." ${ }^{59}$

Damaška trata de transplantes jurídicos específicos na sistemática das provas no processo penal. E o direito probatório, a partir do pano de fundo da dicotomia entre processo penal adversarial e processo penal de matriz inquisitória é campo fértil para a abordagem dos transplantes jurídicos, como se notou inclusive nos textos dos demais autores de processo penal comparado aqui pesquisados.

Como se viu até aqui, também essas escolhas metodológicas, de se cuidar da comparação em ponto-a-ponto (por exemplo, em matéria de disciplina na colheita da prova, cross examination na colheita da prova oral, comportamento do juiz e das partes, acordo de penas e culpa, ou em matéria de oralidade em audiências, sistemática de provas lícitas e ilícitas e assim sucessivamente), ou de usar determinados exemplos para situá-los dentro do pano de fundo objeto de estudo (matriz inquisitória ou adversarial do processo penal, como faz com destaque Maximo Langer), são válidas. Mais do que isso, como demonstram os textos de Langer e Elisabetta Grande, são complementares.

Neste texto se delimita a abordagem crítica no pastiche lembrado por Damaška. O ponto não é escolher "um" ou "mais de um" tema e desenvolver o estudo comparado a seu propósito, com o que a comparação esgotar-se-ia no tema particular em si. A escolha de um ou outro exemplo tem o caráter meramente indicativo do transplante jurídico.

O exercício da utilização do direito comparado no campo processual penal, ainda que não para importar (transplantar) ideias estrangeiras, não é surpresa no Brasil.

59 DAMAŠKA, Mirjan. The uncertain fate of evidentiary transplants: Anglo-American and Continental Experiments. The American Journal of Comparative Law, v. 45, n. 4, p. 839-852, 1997. p. 852. 
Mesmo antes das lições de Alan Watson - segundo quem, grosso modo, além de comuns, os transplantes jurídicos são em grande medida a principal fonte de desenvolvimento dos sistemas jurídicos de cada país $^{60}$ - havia a análise modelar de sistemas distintos para a reflexão sobre reformas no Brasil.

Prova disso é a Exposição de Motivos ao vigente Código de Processo Penal brasileiro (Decreto-Lei 3.689, de 03. 10.1941), do ex-Ministro da Justiça Francisco Campos, no qual se viu a transposição de regras que conformaram a redação do Codice di Procedura Penale italiano de 1930, do ex-Ministro da Justiça Alfredo Rocco.

Francisco Campos disse na Exposição de Motivos que "quando da última reforma do processo penal na Itália, o Ministro Rocco, referindo-se a algumas dessas medidas e outras análogas, introduzidas no projeto preliminar, advertia que elas certamente iriam provocar o desagrado daqueles que estavam acostumados a aproveitar e mesmo abusar das inveteradas deficiências e fraquezas da processualística penal até então vigente. A mesma previsão é de ser feita em relação ao presente projeto, mas são também de repetir-se as palavras de Rocco: 'já se foi o tempo em que a alvoroçada coligação de alguns poucos interessados podia frustrar as mais acertadas e urgentes reformas legislativas."”1

O Código de 1941 foi gestado sob a égide da ideologia inspirada no Codice italiano de 1930, e as cargas dessa transposição de ideias podem

60 WATSON, Alan. Legal transplants. An Approach to Comparative Law. 2. ed. London: University of Georgia Press, 1993. p. 95. Destaca-se, entre os autores que se debruçaram sobre a construção teórica de Francisco Campos, as influências que ele recebeu fora do processo penal projetado na época e as que ele exerceu dentro do diploma legislativo de então, o seguinte artigo: MALAN, Diogo Rudge. Ideologia Política de Francisco Campos: influência na legislação processual penal brasileira (1937-1941). In: PRADO, Geraldo; MALAN, Diogo (Orgs.). Autoritarismo e processo penal brasileiro. Rio de Janeiro: Lumen Juris, 2015. Na p. 46 o autor afirma: "malgrado Francisco Campos nunca tenha se declarado fascista, ou assumido abertamente a influência do regime de Benito Mussolini na ordenação jurídica do Estado Novo, é sintomática a referência feita pela Exposição de Motivos do Estatuto de 1941 ao Ministro da Justiça italiano Alfredo Rocco, grande artífice do Codice di Procedura Penale de 1930."

61 Exposição de Motivos do Código de Processo Penal Brasileiro, item II, segundo parágrafo. 
ser vistas em matérias como gestão da prova pelo juiz e o tratamento de nulidades. Não irá aqui se descer às minúcias do que era a disciplina originária em 1941, mas apenas se trata da coerência, que guiou a exposição de motivos em mais de uma passagem, e foi transposta para o Código antes das sucessivas que reformas que sofreu até os dias atuais.

Ou seja: mesmo que um dos ideários do Código de 1941 fosse a uniformização da sistemática processual penal anterior ${ }^{62}$, a harmonia a partir de uma ideia central, de um fio condutor, de um modelo a ser transplantado, enfim, foi característica do Código gestado pelo conhecido ideólogo do Estado Novo.

Sobre gestão da prova se previa, na Exposição de Motivos (item VII, segundo parágrafo), que "o juiz deixará de ser um espectador inerte na produção de provas. Sua intervenção na atividade processual é permitida, não somente para dirigir a marcha da ação penal e julgar, a final, mas também para ordenar, de ofício, as provas que lhe parecerem úteis ao esclarecimento da verdade.” A ideia originária se espalha pelo capítulo probatório a partir da redação originária do art. 156, revogado em $2008^{63}$. A coerência com a possiblidade de o juiz atuar como interessado podendo para tanto agir de ofício em busca "da verdade" aparece em outras passagens originais do Código de 1941, como por exemplo em matéria de verificação de falsidade (art. 147), determinação de diligências para dirimir dúvidas sobre ponto relevante (art. 156), busca e apreensão (art. 242).

Em matéria de nulidades processuais, a Exposição de Motivos cuidou, no item XVII, de blindar o Código de Processo Penal ao que chamou

62 A Constituição de 1891 previa que à União competia legislar sobre "direito civil, commercial e criminal da Republica e processual da justiça federal" (art. 34, § 23). Por essa distinção final, a competência para legislar sobre processo penal que não fosse da justiça Federal seria dos Estados. A propósito dessa interpretação, João Barbalho Cavalcanti, Constituição Federal Brasileira (1891): comentada. Brasília: Senado Federal. 2002. Edição fac-similar, p. 128. Com a Constituição de 1934 se passou a prever a competência legislativa exclusiva da União para legislar em matéria de direito processual (art. 5, XIX, "a") e, no art. 11, do Ato das Disposições Constitucionais Transitórias se cuidou da comissão de especialistas para elaborar um projeto de Código de Processo Penal.

63 Redação original: “A prova da alegação incumbirá a quem a fizer, mas o juiz poderá, no curso da instrução ou antes de proferir sentença, determinar, de ofício, diligências, para dirimir dúvida sobre ponto relevante". 
de "excessivo rigorismo formal, que dá ensejo, atualmente, à infindável série das nulidades processuais." E prosseguiu abertamente e outra vez com advertência de doutrina italiana (agora sem citar nominalmente o autor), para se fidelizar com a matriz do Codice di Procedura Penale de 1930: "segundo a justa advertência de ilustre processualista italiano, 'um bom direito processual penal deve limitar as sanções de nulidade àquele estrito mínimo que não pode ser abstraído sem lesar legítimos e graves interesses do Estado e dos cidadãos."”

Prosseguiu ainda, a Exposição de Motivos: “O projeto não deixa respiradouro par o frívolo curialismo, que se compraz em espiolhar nulidades. É consagrado o princípio geral de que nenhuma nulidade ocorre se não há prejuízo para a acusação ou a defesa. Não será declarada a nulidade de nenhum ato processual, quando este não haja influído concretamente na decisão da causa ou na apuração da verdade substancial. Somente m casos excepcionais é declarada insanável a nulidade.” As previsões do pórtico do Código, nesse particular, encontram-se espelhadas, desde 1941 até hoje, nos artigos 563 a 574.

A matriz autoritária do Código de Processo Penal de 1941 se refletia, entre outras matérias, nessas acima resenhadas. De lá para cá, o sistema processual penal brasileiro tem experimentado modificações as mais diversas, sejam no próprio Código, sejam por leis especiais.

No corpo do Código de Processo Penal, houve onda reformista que culminou em leis de 1996 (Lei 9.271, alterou a sistemática de citação por edital e tratou de suspensão do curso processual se o acusado não constituir advogado), 2003 (Lei 10.792/2003, reformulou a sistemática do interrogatório), 2008 (Leis 11.689, 11.690, 11.719, que alteraram as sistemáticas do procedimento do júri, das provas e dos procedimentos) e 2011 (Lei 12.403, que reformulou a sistemática das medidas cautelares pessoais no processo penal).

Outras alterações legislativas inovaram no funcionamento do sistema processual penal brasileiro, como foi o caso da Lei 9.099/95 (instituiu os juizados especiais criminais e trouxe ao debate nacional o instituto da justiça negociada com os institutos da transação penal, da composição civil de danos e da suspensão condicional do processo) e, recentemente, a Lei 12.850/13, que nomeia alguns chamados "meios de obtenção de prova”, particularmente a colaboração premiada (art. $4^{\circ}$ ). 
Além da onda reformista presenciada nos últimos 20 anos, vivencia-se pretensão de alterações também em matéria de provas e nulidades processuais, como se iniciou a partir do chamado "Pacote anticorrupção" encabeçado e divulgado por parcela do Ministério Público da União (medida nomeada de "ajustes das nulidades" ${ }^{64}$ ), que redundou em propositura de alteração legislativa em curso no Congresso Nacional ${ }^{65}$.

Distintamente do que se percebeu originariamente, a partir da Exposição de Motivos e das consagrações no Código de Processo Penal até os idos dos anos 90 do século passado, a onda de reformas pontuais dos últimos anos, e por último até a promessa de edição de novo Código de Processo Penal ${ }^{66}$, padecem da falta de um fio condutor em termos de transplantes jurídicos.

Com isso se volta a uma das abordagens escolhidas neste texto, que é a análise crítica do "antes" e do "depois" dos transplantes. Em processo penal, o que motiva o recorte inicial do texto, e até aqui desenvolvido, é o cuidado com a transposição mesma dos modelos jurídicos de um a outro lugar. Não se diagnosticou a prevalência de uma ideia advinda de determinado país a ser transposta para o Brasil. Olha-se para fora daqui sem se ter - ou ao menos se justificar - qualquer critério para se 'pegar' ou 'catar' esse ou aquele modelo e trazê-lo para cá.

Assim, por exemplo, as alterações pontuais sobre a garantia do exercício ao silêncio e a nova previsão de citação por edital não têm sua raiz de ser exclusivamente a partir da consagração de determinado modelo de justiça criminal. Amparam-se em lições antitéticas à raiz do Código de Processo Penal de 1941 e à sua Exposição de Motivos, por força do advento da Constituição Federal de 1988.

64 Medida 7, nomeada de 'ajustes nas nulidades penais contra a impunidade e a corrupção'. Disponível em: <http://www.dezmedidas.mpf.mp.br/apresentacao/conheca-as-medidas/docs/medida_7_versao-2015-06-25.pdf>. Acesso em: 22 nov. 2017. PL 99/2016, de autoria do Senador Randolfe Rodrigues.

66 PL 8045/2010. O autor deste artigo coordenou estudo no âmbito do Instituto Brasileiro de Ciências Criminais que, pontualmente, apreciou os dispositivos do aludido projeto de lei. Disponível em: <https://www.ibccrim. org.br/docs/2017/20170601_ReformaCPPIBCCRIM.pdf>. Acesso em: 22 nov. 2017. 
Pode até se sinalizar por encaminhamento da elaboração de normas processuais penais em obediência a ditames convencionais, como se vê por exemplo, da crescente relevância que se dá no Brasil aos precedentes da Corte Interamericana de Direitos Humanos ou mesmo do Tribunal Europeu dos Direitos do Homem. Ainda assim, não se pode falar de autêntico transplante jurídico.

Já as alterações elaboradas em matéria da chamada justiça consensual, que tiveram início com a Lei 9.099/95 e culminaram com a Lei $12.850 / 13^{67}$ significam virada processual penal ao chamado sistema de common law, notadamente com retórica de modelo processual penal adversarial.

A propósito dessa decorrência, conquanto a doutrina processual penal mais recente tenha alguma preocupação, o ponto específico do transplante jurídico operado, e a lupa do direito comparado mais arguta é a de Marcos Zilli, segundo quem "o fenômeno e o seu estudo foram muito bem captados por Langer. Ainda que adaptada à realidade cultural do organismo receptor, a incorporação de fórmulas processuais fiéis a outro modelo traz o risco da imprevisibilidade. É que na operação diária, a cargo de sujeitos imersos em outra cultura processual, potencializam-se as probabilidades para as distorções. Assim, a invasão pode levar o sistema receptor a um ponto mais próximo daquele que o inspirou. Em situações mais graves, as distorções podem produzir um novo modelo que não é captado pelas tradicionais classificações. São as armadilhas dadas pelo presente grego." ${ }^{\circ}$

67 A escalada legislativa é sintomática do ponto de vista das condutas que podem ser objeto de negociação: inicialmente aquelas de 'menor potencial ofensivo', nos termos do art. 61 e ss, da Lei 9099/95; e já agora, com a colaboração processual que é modelo distinto de acordo entre acusação e defesa, chega-se às raias dos chamados crimes praticados por 'organizações criminosas', que tem sensível patamar de pena abstrata (reclusão de 3 a 8 anos).

68 No acordo de colaboração entre gregos e troianos o cavalo é o prêmio, p. 3. Em texto distinto, e apegado ao procedimento abreviado argentino e a difusão dos "acordos de pena" no processo penal, Maximo Langer explora a ideia de "cavalo de Tróia” como metáfora que significa a mudança de paradigma de sistema processual penal baseado em investigação oficial de um lado, e na disputa entre os envolvidos, de outro lado (LANGER, Maximo. La dicotomia acusatorio-inquisitivo y la importación de mecanismos procesales de la tradición jurídica anglosajona. Algunas reflexiones a partir del procedimento 
E, por fim, o tratamento que se pretende dar à sistemática das provas no processo penal - aí incluída a gestão da prova e os papéis que se espera sejam desenvolvidos pelos atores processuais penais: juiz e partes, bem como das provas ilícitas a partir da inauguração constitucional de $1988^{69}$ - é tributário, da mesma forma, de certa (ou ao menos imaginada) aproximação ao modelo de common law.

Isso, seja do que se vê consagrado por força da Lei 11.690/08 que alterou a redação dos artigos 155 e seguintes do Código de Processo Penal brasileiro e deu inédito tratamento infraconstitucional à matéria das provas ilícitas, suas consequências e as purgações de vícios; seja também do que se percebe dos projetos de lei em curso no Congresso Nacional na já aludida questão de provas ilícitas e nulidades ${ }^{70}$.

abreviado. In: MAIER, Julio B. J.; BOVINO, Alberto (comps.). El Procedimento Abreviado. Editores del Puerto: Buenos Aires, 2001, p. 124. Sobre os acordos, também chamados de barganhas, no processo penal brasileiro, ver: VASCONCELLOS, Vinicius G. Barganha no processo penal e o autoritarismo "consensual” nos sistemas processuais: a justiça negocial entre a patologização do acusatório e o contragolpe inquisitivo. Revista dos Tribunais, São Paulo, n. 953, p. 261-279, mar. 2015.

69 Art. 5, LVI: "São inadmissíveis, no processo, as provas obtidas por meios ilícitos."

70 No PL 99/2016, que pretende disciplinar as matérias sobre provas ilícitas e nulidades no processo penal, a matéria é tratada com reducionismo teórico que custa crer seja digno de justificativa, tamanha a desproporção entre a complexidade do assunto junto à tão sensível a alteração proposta ao longo de diversos dispositivos processuais penais e a superficialidade com que se tratou de ambos. Cogita-se, nas justificativas, de abordar a inadmissibilidade de provas ilícitas como se não passassem de "regras não escritas na lei”, a partir de abordagem míope porque abertamente tributária exclusivamente do apego ao disseminado entendimento de que as exclusionary rules teriam somente um efeito dissuasório (proteção contra más práticas policiais que violem a $4^{\mathrm{a}}$ e $5^{\mathrm{a}}$ Emendas), descuidando-se do arcabouço teórico que trata de métodos proibidos de prova e efeitos distintos do meramente dissuasório. Não se trata numa linha sequer nem mesmo das distintas possibilidades de consequências processuais penais advindas do reconhecimento de vícios em matéria probatória. As justificativas utilizadas na proposta, todas elas, decorrem do apego irrestrito a concepção do processo penal norte americano, inclusive o rol que se pretende inserir de outras fórmulas que esvaziariam a previsão de contaminação de ilicitudes probatórias. Em matéria de nulidades, o citado PL revivesce a exposição de motivos de 1941, com o esforço de evitar ao máximo o desfazimento de atos processuais. Nesse tema, não há transplante algum do sistema norte-americano, mas pura e 
O direito processual penal brasileiro atual convive, de um lado, com o ideal ainda vigente em larga medida de regras inquisitórias do Código de Processo Penal de 1941, e, de outro, com alterações que ora privilegiam a introjeção de valores diretamente constitucionais, e ora decorrem de abertos transplantes jurídicos. Essa é a aporia que se pode diagnosticar, no encaminhamento conclusivo das abordagens deste texto.

Foi visto e defendido aqui que o transplante jurídico, mesmo que com alterações radicais do ponto de vista sistemático, não seria em si problemático. A crítica sempre pode acontecer diante de alguma radicalidade pela adoção tout court de um modelo em detrimento de outro, mas há justificativa (deve haver) para tanto, se o espírito do transplante é, mesmo, modificar determinado sistema jurídico. No limite, portanto, a resposta às críticas nesse pormenor seriam que as alterações seriam mesmo propositais.

Acontece que, justamente por se tratar de alteração sistemática, o cuidado mínimo que se deve ter é com a alteração como um todo, e não em pontos cirúrgicos, deixando as indeléveis marcas de sistema jurídico incompatível vigente com as alterações propostas.

Em ainda nova metáfora: uma coisa é o transplante, outra é a introjeção de órgão estranho, incompatível, algo que se aproxima de um irresponsável enxerto, num pedaço do corpo, que passará a não funcionar bem como o enxerto não pensado para todo o organismo. O transplante pode ter razões para funcionar ou não, a depender de como se reage às modificações legislativas; mas com o corpo estranho não se tem método algum na introjeção das novas normas e nem o mínimo cálculo do que pode advir da operação.

simplesmente o discurso salvacionista de aproveitamento de possíveis atos processuais nulos em desconsideração até mesmo aos entendimentos dos próprios autores dos Estados Unidos que chegam a propor caminhos intermediários à aplicação tout court de regras de exclusão. No mesmo Projeto de Lei, portanto, caminha-se ora num sentido (transplante jurídico de precedentes dos EUA), ora noutro, que com ele não tem qualquer relação (tratamento de nulidades, na esteira da Exposição de Motivos de 1941). Sobre alguns dos exemplos vistos já acima, mas particularmente cuidando da sistemática das provas, vale ver: MOREIRA, José Carlos Barbosa. O processo penal norte-americano e sua influência. Revista Brasileira de Direito Comparado, n. 19. p. 227-245, jul./dez. 2000. 
Assim, por exemplo, em matéria da lenta e propalada adversarialização que se pode dizer ser uma das tônicas do processo penal brasileiro atual $^{71}$, não há como, por exemplo, conviverem no mesmo organismo jurídico, previsões como a do art. 257, do Código de Processo Penal (o Ministério Público pode ser tanto parte em ações penais públicas, como "fiscal da lei"), e aquelas que se ligam à justiça negociada, que são a tônica de algumas das mais recentes alterações legislativas.

Ainda nessa tônica, a consideração tão consagrada quanto irrefletida da assunção do Ministério Público como "fiscal da lei" se divorcia da ideia de processo penal de partes - que é o que justifica empiricamente a justiça consensual - em matéria recursal, com o oferecimento de pareceres em ações penais de iniciativa pública, como sobreposição aos arrazoados já constantes do mesmo órgão, quando atuante a título de parte no processo.

O curioso é se perceber que, sabendo-se ou não de raiz de as coisas serem distintas como são num e noutro país, a transposição dos modelos de atuação das partes em matéria de justiça negociada desconsidera absolutamente que o berço de onde a modificação vem (os Estados Unidos da América) têm no Ministério Público órgão cujos representantes são eleitos e prestam contas à sociedade de forma diversa do que há aqui,

71 VIEIRA, Renato Stanziola. Traços adversariais no Projeto de Código de Processo Penal. Uma proposta par o estudo da paridade de armas. In: MALAN, Diogo; MIRZA, Flávio (Coords.). 70 Anos do Código de Processo Penal Brasileiro. Balanço e perspectivas de Reforma. Rio de Janeiro: Lumen Juris. 2011. p. 361402. O tema específico do processo adversarial e inclusive os enfoques que podem justificar ser o sistema adversarial do sistema acusatório é muito mais complexo do que aqui se poderia resumir. Para aprofundamento, sugere-se a consulta às seguintes obras: TARUFFO, Michelle. El proceso civil adversarial en la experiencia americana: el modelo americano del proceso de conotación dispositiva. Trad. Beatriz Quintero. Bogotá: Temis, 2008. LANDSMAN, Stephan. Brief survey of the development of the adversary system.. LANGBEIN, John $\mathrm{H}$. The origins of adversary criminal trial. New York: Oxford University Press, 2003. VOGLER, Richard. El sistema acusatorio en los procesos penales en Inglaterra y en Europa continental. In: WINTER, Lorena Bachmaier (Coord.). Proceso penal y sistemas acusatorios. Madrid, Barcelona, Buenos Aires: Marcial Pons, 2008. VOGLER, Richard. Adversarialidad y el dominio angloamericano del proceso penal. In: AMBOS, Kai, LYNETT, Eduardo Montealegre (Comp.). Constitución y sistema acusatorio: un estudio de derecho comparado. Bogotá: Universidad Externado de Colombia, 2005. DAMAŠKA, Mirjan. Models of Criminal Procedure, pp. 477-516; DAMAŠKA, Mirjan. Evidence Law Adrift. New Haven \& London: Yale University Press, 1997. 
a partir da Constituição Federal de 1988. É decididamente impensável, como se vê por esses exemplos, olhar para a modificação processual penal propalada sem se modificar a estrutura sob a qual se constrói o ainda vigente modelo brasileiro. Não há como se vestir a mesma roupa se o corpo muda.

Da mesma forma, como se tem percebido aproximação também em questão de comportamento judicial com o sistema adversarial de processo penal, em que o juiz tem mais o papel de árbitro do que de investigador em busca da dita verdade real, a previsão ainda de poderes instrutórios ex officio ao lado de previsões de livre disponibilidade das partes em matérias probatórias é outro complicador e sinalizador de que não se sabe o que se transplanta no Brasil.

Outro exemplo da pequena reflexão técnica sobre os transplantes jurídicos no Brasil se nota na pretensão de, com o advento de futuro Código de Processo Penal, instituir-se aqui a chamada investigação defensiva, que também tem como raiz o sistema norteamericano de processo penal e foi acolhida na Itália com reforma legislativa de 2000.

De um lado se imagina aproximação ao modelo de disponibilidade dos envolvidos de irem à cata de elementos de informação autonomamente mas, aqui, isso não seria acompanhado de alteração no vetusto artigo 14, do CPP, que prevê ser atribuição exclusiva do Delegado de Polícia o deferimento ou não de diligências a serem tomadas pela defesa, isso sem falar na própria limitação da própria atividade em si, quando comparada com a imaginada nos modelos paramétricos do transplante ${ }^{72}$.

Há outros exemplos que poderiam ser lembrados inclusive apegados à má prática dos próprios atores do sistema jurídico em lidar com normas já advindas de reforma como por exemplo se vê com a ordem de perguntas a serem feitas às testemunhas prevista no art. 212 do Código de Processo Penal, desconsiderada amiúde pelos próprios Magistrados.

72 VIEIRA, Renato Stanziola. Investigação defensiva: diagnóstico e possibilidades no processo penal brasileiro. In: AMBOS, Kai; MALARINO, Ezequiel; VASCONCELOS, Eneas Romero de (Coords.). Polícia e investigação no Brasil. Brasília: Gazeta Jurídica, 2016. p. 337-72; MALAN, Diogo Rudge. Investigação defensiva no processo penal. Revista Brasileira de Ciências Criminais, a. 20, v. 96, 2012 
O que aqui se pretende é apenas ilustrar que o transplante jurídico não é, em si mesmo, o ponto da crítica. O problema reside na não convivência harmônica das normas que não são alteradas com o advento das reformas. E essa crítica mina a eficiência pretendida de qualquer reforma, e também fulmina - sob qualquer prisma - a possibilidade de êxito e funcionalidade do transplante jurídico (ao menos se se parte da premissa de que se pretende efetivamente atingir alguma mudança com a nova legislação).

Outro detalhe é que as próprias mudanças não são, por vezes, precedidas de diagnósticos precisos sobre a funcionalidade do sistema no próprio país de origem. Vale lembrar da crítica feita pela própria doutrina processual penal norte americana sobre os vícios inerentes às práticas de justiça consensual (que vão da 'overcharging' à extorsão de confissão pura e simples às considerações sobre como o modelo mina $\mathrm{o}$ aspecto do contraditório inerente à noção mesma de processo $)^{73}$, não refletidas majoritariamente no $\mathrm{Brasil}^{74}$, que tem se tornado receptáculo fértil dessas mesmas ideias.

\section{Conclusões}

Carmen Miranda, que imortalizou a canção cujo trecho serviu de epígrafe a este trabalho, cantou sobre o repto que sofreu por ter ficado "muito rica" e não suportar mais "o breque do pandeiro", mas se defendeu cantando que "diz mesmo eu te amo e nunca "I love you"”, e que "enquanto houver Brasil na hora da comida eu sou do camarão ensopadinho com chuchu."

A típica mistura do que é nosso e do que é de fora é o que acontece com o processo penal brasileiro, desbaratado ante reformas que propalam

73 STUNTZ, William J. The collapse of American criminal justice. Cambridge, London: The Belknap Press of Harvard University Press, 2011.

74 Dentre as vozes que excepcionam esse silêncio está a de PRADO, Geraldo. Elementos para uma análise crítica da transação penal. Rio de Janeiro: Lumen Juris, 2003. Também como marco crítico, o trabalho de VASCONCELLOS, Vinícius Gomes de. Barganha e Justiça Criminal Negocial. Análise das tendências de expansão dos espaços de consenso no processo penal brasileiro. São Paulo: IBCCRIM, 2015. 
seguir modelos de tendência retórica adversarial, mas que não esconde o viés autoritário e inquisitório ainda reinante aqui consagrado no Código vigente, e nem mesmo se questiona sobre as virtudes e defeitos no funcionamento do modelo transplantado no país de origem.

Esforçou-se no texto para, na seção própria em que se pretendeu tratar da abordagem teórica dos transplantes jurídicos do ponto de vista do direito comparado, contextualizar tanto a inevitabilidade do método e de seus efeitos práticos, quanto do juízo crítico que deve permear a admiração de um ou outro modelo. Essa pretensão veio acompanhada de uma contextualização das reformas processuais penais da América Latina nos últimos 30 anos, que coincidiu com a onda reformista do processo penal dos países latinoamericanos.

Pode parecer uma separação metodológica criticável a abordagem entre, de um lado, transplantes jurídicos e explorações conceituais correlatas e, de outro, o posicionamento sobre as motivações que redundaram na apropriação de determinados países (latinoamericanos) de regras jurídicas vindas de outros (o discurso "sul-norte"). Mas pareceu ser útil a junção dessas duas abordagens porque a conexão entre o sul e o norte se dá justamente (e inclusive) pelos transplantes jurídicos.

Esclarecido isso, as escolhas de conformações legislativas do processo penal brasileiro em tempos recentes são uma mistura de falta de cuidado de diagnóstico (com o que existe e se quer transplantar) e falta de responsabilidade no prognóstico (pois não há como se acomodarem modelos tão estranhos dentro do mesmo sistema jurídico enquanto a mimetização não passar de um aproveitamento tópico, sem qualquer justificativa e nem muito menos com compromisso com a estrutura na qual determinada norma estrangeira passará a incidir).

Por isso mesmo é que a preocupação é (ou deveria ser) com o que vem depois dos transplantes jurídicos. Mais de uma vez se afirmou no texto: o problema não é, em si mesmo, a ideia de transplante jurídico (a crítica que pode ser feita a isso é a de neocolonialismo, emulação por espírito de subserviência cultural, dependência econômica etc.), e sim, de "qual" transplante se trata, de "qual extensão" de determinado sistema se propõe alterar.

Miscelânea de ideias pode ser algo intuitivamente positivo na busca de melhores soluções para possível conformação legislativa. Mas 
não é de miscelânea que se cuida, e sim de pólos que podem ser, nos exemplos discutidos na parte final deste texto, mutuamente repelentes.

Por tudo isso, repete-se o que se disse na introdução: não se quer avançar com a propositura de soluções ou de forma arrogante propor "o melhor" transplante ou coisa parecida.

O caminho que se trilha em termos de utilização de direito processual penal comparado no Brasil é errático, de ininteligível motivação, e deve ser repensado. Não se discute se, por determinada opção político-criminal, um sistema processual e suas características deva ser visto como melhor ou pior do que outro.

No Brasil a importação acrítica de pedaços de sistemas jurídicos - seja pelo não compromisso sistemático, seja pela falta de justificativa inclusive da escolha do modelo a se seguir sem se questionar sequer sua funcionalidade na origem - destrói a racionalidade do nosso próprio sistema processual penal.

Desconfigura-se o que existe - o que por si só impede de formular crítica responsável para a própria reformulação - e não há fidelidade ao modelo inicial que é aqui transplantado. Não se constrói sistema algum.

\section{BibLIOGRAFIA}

ANITUA, Gabriel Inácio. La Importación de Mecanismos Consensuales del Proceso Estadounidense, en las Reformas Procesales latinoamericanas. Revista Brasileira de Direito Processual Penal, Porto Alegre, v. 1, n. 1. p. 43-65, 2015. http://dx.doi. org/10.22197/rbdpp.v1i1.3

BARBOSA MOREIRA, José Carlos. O processo penal norte-americano e sua influência. Revista Brasileira de Direito Comparado. Instituto de Direito Comparado luso-brasileiro, Rio de Janeiro, n. 19, p. 227-245, 2001.

CAIRNS, John W. Watson, Walton, and the History of Legal Transplants. Georgia Journal of International and Comparative Law, v. 41, n. 3, p. 637-696, 2014.

CAVALCANTI, João Barbalho Uchôa. Constituição Federal Brasileira (1891): comentada. Brasília: Senado Federal, 2002.

DAMAŠKA, Mirjan. The faces of justice and State authority: a comparative approach to the legal process. New Haven \& London: Yale University Press, 1986. 
DAMAŠKA, Mirjan. The uncertain fate of evidentiary transplants: Anglo-American and Continental Experiments. The American Journal of Comparative Law, v. 45, n. 4, p. 839-852, 1997. https://doi.org/10.2307/841021

DAMAŠKA, Mirjan. Evidence Law Adrift. New Haven \& London: Yale University Press, 1997.

DAMAŠKA, Mirjan. Models of Criminal Procedure, 51 Zbornik PFZ 477, p. 477516, 2001.

ESQUIROL, Jorge L. The Failed Law of Latin America. The American Journal of Comparative Law, v. 56. n. 1, p. 75-124, 2008. https://doi.org/10.5131/ajcl.2007.0003

ESQUIROL, Jorge L. Las ficciones del derecho latinoamericano. Bogotá: Siglo del hombre editores, 2014.

ESQUIROL, Jorge L. El nuevo latinoamericanismo jurídico. In: BONILLA MALDONADO, Daniel (org.). Geopolítica del conocimiento jurídico. Bogotá: Siglo del Hombre Editores, 2015.

FOJANTI, Lena. Legal Transfers as Processes of Cultural Translation: On the Consequences of a Metaphor. Max Planck Institute for European Legal History. Research Paper Series n. 2015-09, p. 1-18, 2015.

HOBSBAWN, Eric. Viva la Revolución. A era das utopias na américa latina. Trad. Pedro Maia Soares. São Paulo: Companhia das Letras, 2017.

GLENN, Patrick H. On the use of biological Metaphors in Law: the case of Legal Transplants. The Journal of Comparative Law, p. 358-364, 2006.

GRANDE, Elisabetta. Legal Transplants and the inoculation effect. How American criminal procedure has affected continental Europe. The American Journal of Comparative Law, v. 64, p. 583-618, 2016. https://doi.org/10.1093/ajcl/avw004

GRAZIADEI. Michele. Comparative Law as the Study of Transplants and Receptions. In: REINMANN, Mathias; ZIMMERMANN, Reinhard (eds.). The Oxford Handbook of Comparative Law. Oxford: Oxford University Press, 2006. https:// doi.org/10.1093/oxfordhb/9780199296064.013.0014

KAHN-FREUND, Otto. On uses and misuses of comparative law. The Modern Law Review, v. 37, n. 1, p. 1-27, jan. 1974. http://dx.doi.org/10.1111/j.1468-2230.1974. tb02366.x

LANDSMAN, Stephan. Brief survey of the development of the adversary system. Ohio State Law Journal, n. 44, p. 713-739, 1983. 
LANGBEIN, John H. The origins of adversary criminal trial. New York: Oxford University Press, 2003. https://doi.org/10.1093/acprof:oso/9780199287239.001.0001

LANGER, Maximo. La dicotomia acusatorio-inquisitivo y la importación de mecanismos procesales de la tradición jurídica anglosajona. Algunas reflexiones a partir del procedimento abreviado. In: MAIER, Julio B. J.; BOVINO, Alberto (comps.). El Procedimento Abreviado. Editores del Puerto: Buenos Aires, 2001.

LANGER, Maximo. From Legal Transplants to Legal Translations: The Globalization of Plea Bargaining and the Americanization Thesis in Criminal Procedure. Harvard International Law Journal, v. 45, n. 1, p. 1-64, 2004.

LANGER, Maximo. Revolution in Latin American Criminal Procedure: Diffusion of Legal Ideas from the Periphery. The American Journal of Comparative Law, v. 55, n. 4, p. 617-676, 2007. https://doi.org/10.1093/ajcl/55.4.617

LANGER, Maximo. In the beginning was Fortescue: on the Intelectual Origins of the Adversarial and Inquisitorial Systems and Common and Civil Law in Comparative Criminal Procedure. In: ACKERMAN, Bruce; AMBOS, Kai; SIKIRIĆ, Hrvoje (eds.). Visions of Justice. Liber Amicorum Mirjam Damaška. Berlim: Cunker \& Humblot, 2016.

LEGRAND, Pierre. The Impossibility of legal transplants. Maastricht Journal of European and Comparative Law, v. 4, n. 2, p. 111-124, jun. 1997. https://doi. org/10.1177/1023263X9700400202.

MALAN, Diogo Rudge. Investigação defensiva no processo penal. Revista Brasileira de Ciências Criminais, a. 20, v. 96, 2012.

MALAN, Diogo Rudge. Ideologia Política de Francisco Campos: influência na legislação processual penal brasileira (1937-1941). In: PRADO, Geraldo; MALAN, Diogo (Orgs.). Autoritarismo e processo penal brasileiro. Rio de Janeiro: Lumen Juris, 2015.

MALDONADO, Daniel Bonilla. Introducción. Teoria del Derecho y Transplantes Juídicos: la estrutura del debate. In: MALDONADO, Daniel Bonilla (Ed.). Teoria del Derecho y transplantes jurídicos. Bogotá: Siglo del Hombre Editores, 2009.

MALDONADO, Daniel Bonilla. Constitucionalism of the Global South. The Activist Tribunals of India, South Africa, and Colombia. Cambridge: Cambridge University Press, 2013.

MATTEI, Ugo. A theory of imperial law: a study on U.S. hegemony and the Latin resistance. Indiana Journal of Global Legal Studies, vol. 10, n. 1, p. 382-448, 2003. 
NELKEN, David. The Meaning of Success in Transnational Legal Transfers. 19 Windsor Yearbook of Access to Justice, p. 349-66, 2001.

NELKEN, David. Comparatists and transferability. In: LEGRAND, Pierre; MUNDAY, Rodrick (Eds.). Comparative Legal Studies: Traditions and Transitions. Cambridge: Cambridge University Press, 2003.

PRADO, Geraldo. Elementos para uma análise crítica da transação penal. Rio de Janeiro: Lumen Juris. 2003.

SCHÜNEMAN, Bernd. Um olhar crítico ao modelo processual penal Norte-Americano. In: SCHÜNEMAN, Bernd; GRECO, Luís (coord.). Estudos de direito penal, direito processual penal e filosofia do direito. São Paulo: Marcial Pons, 2013.

STUNTZ, William J. The collapse of American criminal justice. Cambridge, London: The Belknap Press of Harvard University Press, 2011.

TARUFFO, Michelle. El proceso civil adversarial en la experiencia americana: el modelo americano del proceso de conotación dispositiva. Trad. Beatriz Quintero. Bogotá: Temis, 2008.

TEUBNER, Gunther. Legal Irritants: good Faith in British Law or How Unifying Law Ends up in New Divergences. The Modern Law Review, vol. 61, n. 1, p. 11-32, jan. 1998. https://doi.org/10.1111/1468-2230.00125

VASCONCELLOS, Vinicius G. Barganha no processo penal e o autoritarismo "consensual” nos sistemas processuais: a justiça negocial entre a patologização do acusatório e o contragolpe inquisitivo. Revista dos Tribunais, São Paulo, n. 953, p. 261-279, mar. 2015.

VASCONCELLOS, Vinícius Gomes de. Barganha e Justiça Criminal Negocial. Análise das tendências de expansão dos espaços de consenso no processo penal brasileiro. São Paulo: IBCCRIM, 2015.

VIEIRA, Renato Stanziola. Traços adversariais no Projeto de Código de Processo Penal. Uma proposta par o estudo da paridade de armas. In: MALAN, Diogo; MIRZA, Flávio (Coords.). 70 Anos do Código de Processo Penal Brasileiro. Balanço e perspectivas de Reforma. Rio de Janeiro: Lumen Juris. 2011.

VIEIRA, Renato Stanziola. Investigação defensiva: diagnóstico e possibilidades no processo penal brasileiro. In: AMBOS, Kai; MALARINO, Ezequiel; VASCONCELOS, Eneas Romero de (Coords.). Polícia e investigação no Brasil. Brasília: Gazeta Jurídica, 2016. 
VOGLER, Richard. Adversarialidad y el dominio angloamericano del proceso penal. In: AMBOS, Kai; LYNETT, Eduardo Montealegre (Comp.). Constitución y sistema acusatorio: un estudio de derecho comparado. Bogotá: Universidad Externado de Colombia, 2005.

VOGLER, Richard. El sistema acusatorio en los procesos penales en Inglaterra y en Europa continental. In: WINTER, Lorena Bachmaier (Coord.). Proceso penal y sistemas acusatorios. Madrid; Barcelona; Buenos Aires: Marcial Pons, 2008.

WATSON, Alan. Legal transplants. An Approach to Comparative Law. 2. ed. London: University of Georgia Press, 1993.

WEIGAND, Wolfgang. Americanization of Law: Reception or Convergence? In: FRIEDMAN, Lawrence M.; SCHEIBER, Harry N. (eds.) Legal Culture and the Legal Profession, Bouldere: Westview Press, 1996.

ZILLI, Marcos. No acordo de colaboração entre gregos e troianos o cavalo é o prêmio. Boletim do IBCCRIM, n. 300, p. 3-5, nov. 2017.

\section{Informações adicionais e declarações dos autores (integridade científica)}

Declaração de conflito de interesses (conflict of interest declaration): o autor confirma que não há conflitos de interesse na realização das pesquisas expostas e na redação deste artigo.

Declaração de autoria e especificação das contribuições (declaration of authorship): todas e somente as pessoas que atendem os requisitos de autoria deste artigo estão listadas como autores; todos os coautores se responsabilizam integralmente por este trabalho em sua totalidade.

Declaração de ineditismo e originalidade (declaration of originality): o autor assegura que o texto aqui publicado não foi divulgado anteriormente em outro meio e que futura republicação somente se realizará com a indicação expressa da referência desta publicação original; também atesta que não há plágio de terceiros ou autoplágio. 


\section{Dados do processo editorial}

(http://www.ibraspp.com.br/revista/index.php/RBDPP/about/editorialPolicies)

- Recebido em: 26/12/2017

- Controle preliminar e verificação de plágio: 26/12/2017

- Comunicação ao autor do deslocamento ao V4N2: 26/12/2017

- Avaliação 1: 26/02/2018

- Avaliação 2: 04/03/2018

- Avaliação 3: 14/03/2018

- Decisão editorial preliminar: 14/03/2018

- Retorno rodada de correções 1: 22/03/2018

- Decisão editorial preliminar 2: 31/03/2018

- Retorno rodada de correções 2: 04/04/2018

- Decisão editorial final: 07/04/2018

\section{Equipe editorial envolvida}

- Editor-chefe: 1 (VGV)

- Revisores: 3

\section{COMO CITAR ESTE ARTIGO:}

VIEIRA, Renato Stanziola. O que vem depois dos "legal transplants"? Uma análise do processo penal brasileiro atual à luz de direito comparado. Revista Brasileira de Direito Processual Penal, Porto Alegre, vol. 4, n. 2, p. 767-806, mai./set. 2018. https://doi.org/10.22197/rbdpp.v4i2.133

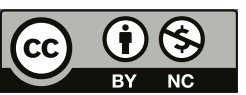

Esta obra está licenciada com uma Licença Creative Commons Atribuição-NãoComercial 4.0 Internacional. 